\title{
An electrophoretic capture method for efficient recovery of rare sequences from heterogeneous DNA
}

\author{
J. Kent Moore, Jean A. Smith, Duncan H. Whitney, Kristine H. Durkee, and \\ Anthony P. Shuber \\ EXACT Sciences Corporation, Marlborough, MA, USA
}

BioTechniques 44:363-374 (March 2008)

doi 10.2144/000112702

It is difficult to isolate rare, PCR-quality DNA from specimens containing large quantities of nonspecific DNA from multiple sources (heterogeneous DNA). Extracting human DNA from stool for colorectal cancer (CRC) screening tests exemplifies this technically challenging sample preparation problem. The stool matrix is complex, the DNA composition heterogeneous, and CRC-associated mutated DNA is rare. This report describes a novel solid phase DNA sequence-specific hybrid capture sample preparation method: the reversible electrophoretic capture affinity protocol (RECAP). We show that RECAP, compared with other methods, is capable of extracting linearly increasing amounts of human DNA from increasing amounts of total stool DNA in a manner that avoids co-purifying PCR inhibitors. RECAP thereby increases the yield of rare mutated DNA molecules and thus increases the detection sensitivity for CRC-associated mutations.

\section{INTRODUCTION}

Detecting rare DNA target molecules in a heterogeneous background of DNA from multiple sources requires the isolation of sufficient DNA targets to exceed the lower limit in sensitivity of the detection assay. Sample aliquots of sufficient size must be processed in order to ensure that the target is present in the aliquot and thus eliminate stochastic sampling error that may lead to false-negative results. The design of a clinical CRC diagnostic assay using stool, an exceedingly complex sample with limited amounts of human DNA, must be able to accommodate large sample aliquots to ensure sufficient target DNA recovery. The most common approach to nucleic acid sample preparation is typically to recover the total DNA or RNA complement of a sample, using ionexchange supports (1-5), glass beads $(6,7)$, and other solid-phase methods $(8-11)$, followed by sequence-specific PCR amplification to enrich for the target of interest. Target amplification can be complicated in samples with heterogeneous DNA populations where the target may be mixed with a majority of nucleic acids from other organisms. The PCR may be unable to amplify sufficient rare target for detection. Simply adding more heterogeneous DNA to the reaction can lead to other undesired results such as mis-priming and PCR inhibition.

Sequence-specific hybridization methods are an efficient way of recovering rare targets directly from heterogeneous DNA samples (12-15). These typically use oligonucleotide capture probes designed to hybridize to the nucleic acid target with subsequent retrieval, such as with the use of a biotinylated capture probe and magnetized beads with immobilized streptavidin (16-18). An early application of sequence-specific capture for detecting mycobacterium in heterogeneous clinical samples $(16,19)$ reported an increase in PCR assay sensitivity of 10- to 100-fold. Improved PCR sensitivity results from significant target enrichment and the reduction of nontarget DNA from the reaction, thus providing more robust detection of rare DNA targets.

The reversible electrophoretic capture affinity protocol (RECAP) is a sequence-specific hybridization capture method driven by electrophoresis that was designed for large volumes of minimally purified complex heterogeneous DNA samples. In this report, we use RECAP to recover increased human DNA quantities from the stool samples of colon cancer patients and investigate if the increased recovery improves the detection sensitivity of rare mutated DNA molecules associated with the colon cancers. For comparison, the mutation detection sensitivity of a magnetic bead-based hybridization capture method and a column-based total DNA purification method is also examined.

\section{MATERIALS AND METHODS}

\section{RECAP Hybrid Capture Process}

The RECAP apparatus (see the Supplementary Material available online at www.BioTechniques.com) is a multi-channel plate fitted with Spectra/ Pro dialysis membrane $(\mathrm{MWCO}=$ 3,500; Spectrum, Rancho Dominguez, CA, USA) at both ends of each individual channel (Figure 1, inset B). The channel plate was placed into a $1 \times$ Tris-Borate-Edta Buffer (TBE)filled A2 Gator electrophoresis gel box (Owl Separation Systems, Portsmouth, NH, USA). The dialysis membranes provided a barrier that retained the DNA samples within each channel while allowing for electrophoresis. For each channel, a DNA capture device (Figure 1, inset A) was placed in the center of the channel, forming two chambers; one filled with sample and the other with $1 \times$ TBE. The capture device contained $100 \mu 1$ UltraLink Plus streptavidin beads (Pierce, Rockford, IL, USA) sandwiched between two layers of medical grade polyester mesh (pore size $=44 \mu \mathrm{m}$; Sefar America, Trenton, NJ, USA), forming a $1.5-\mathrm{mm}$ thick porous layer of packed beads. The beads were activated by applying 200 pmol of biotin-labeled oligonucleotide capture probes in $100 \mu \mathrm{l} \mathrm{ST}$ buffer $(150 \mathrm{mM} \mathrm{NaCl}, 15 \mathrm{mM}$ Tris$\mathrm{HCl}, \mathrm{pH}$ 7.4) across the capture device bead bed with low-speed centrifugation $(1900 \times g)$ using a capture device wash plate (EXACT Sciences, Marlborough, MA, USA). The probe 
solution was recovered from the wash plate, reapplied to the bead bed, and recentrifuged for a total of three times. The activated capture device was then serially washed with ST buffer, $0.1 \mathrm{~N}$ $\mathrm{NaOH}$ followed by ST buffer, using centrifugation as above, to remove nonspecifically bound capture probe. The capture probes (IDT, Coralville, IA, USA) were specific for the human APC gene sequence (Table 1).

Total DNA was isolated from whole human stools that had been previously homogenized in a DNA stabilization buffer (EXACT Sciences) and archived at $-80^{\circ} \mathrm{C}(20)$. A volume of thawed homogenate containing $4 \mathrm{~g}$ of stool (a "4 gm stool equivalent") was centrifuged to remove all particulate matter and treated with RNase A. DNA was precipitated with isopropanol and resuspended in $4 \mathrm{~mL}$ of $1 \times \mathrm{TE}(10 \mathrm{mM}$ Tris $\mathrm{pH} 7.4,1 \mathrm{mM}$ EDTA). DNA for RECAP was prepared in $10 \mathrm{~mL}$ load volumes consisting of $1 \mathrm{~mL}$ of $10 \times$ TBE $(890 \mathrm{mM}$ Tris, $890 \mathrm{mM}$ Boric Acid, $20 \mathrm{mM}$ EDTA), $1 \mathrm{~mL}$ of $10 \%$ SDS, and $8 \mathrm{ml}$ of resuspended total stool DNA. When $<8 \mathrm{ml}$ of DNA were used, the volume was replaced with $1 \times$ TE to achieve a final load volume of 10 $\mathrm{ml}$ containing $1 \times \mathrm{TBE}$ and $1 \%$ SDS. DNA samples were denatured at $95^{\circ} \mathrm{C}$ for $15 \mathrm{~min}$ and then cooled on ice for 15 min prior to loading into the sample channels of the RECAP apparatus.

The RECAP gel box was connected to a power supply directed through a current switching box (EXACT Sciences) and samples were electrophoresed at $150 \mathrm{~V}$. The switch box reversed the current every $90 \mathrm{~min}$ for a total of 14 cycles to repeatedly drive the DNA back and forth through the capture device. The duration of the switch cycle was set to the time required for $90 \%$ of a control DNA sample to transit the capture device at $150 \mathrm{~V}$. After completion of cycling, the capture devices were removed to a wash plate and washed four times with $500 \mu \mathrm{L}$ of ST buffer by low-speed centrifugation $(1 \mathrm{~min}, 1900 \times g)$. The captured human DNA target was eluted by addition of $100 \mu \mathrm{L}$ of $0.1 \mathrm{~N} \mathrm{NaOH}$ followed by low-speed centrifugation. The eluate was neutralized with $10 \mu \mathrm{L}$ of neutralization buffer $(60 \mathrm{mM}$ Tris

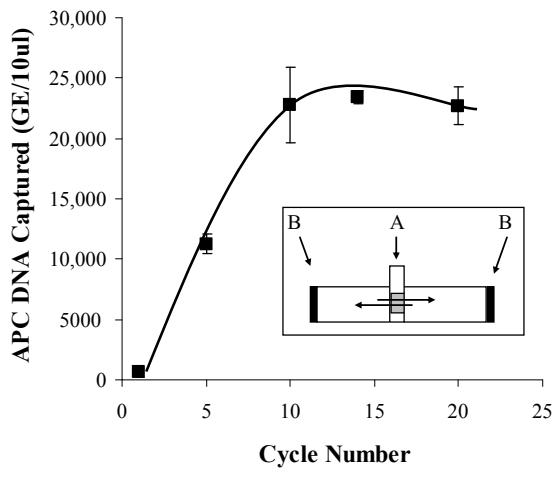

Figure 1. Human APC DNA recovery as a function of electrophoretic capture cycle number. During the RECAP process (inset), the DNA sample is cycled electrophoretically back and forth through the capture cartridge (A). Dialysis membrane on each end of the RECAP channel (B) retains the DNA sample within the device. After 1 , $5,10,14$, or 20 electrophoretic capture cycles, duplicate capture cartridges were removed and target DNA was eluted. The amount of recovered human APC gene from a $5 \mu \mathrm{g}(71,428 \mathrm{GE} / 10 \mu \mathrm{l})$ sample of purified genomic DNA for each cycle timepoint was determined by real-time PCR (average of the duplicates is illustrated). GE, genomic equivalents, 95\% confidence intervals.

Table 1. Sequences of Oligonucleotides Described in This Study

\begin{tabular}{|ll|}
\hline Name & Sequence \\
\hline Human APC capture probes & 5'-CTTCTGCTTGGTGGCATGGTTTGTCCAGGGCTATCTG-3' \\
& 5'-GAACGACTCTCAAAACTATCAAGTGAACTGACAGAAG-3' \\
& 5'-GCATTTACTGCAGCTTGCTTAGGTCCACTCTCTCTCT-3' $^{\prime}$ \\
& \\
APC forward primer & $5^{\prime}$-AGCCCCAGTGATCTTCCAGAT-3' \\
APC reverse primer & $5^{\prime}$-AGGTGGTGGAGGTGTTTTACTTCT-3' \\
APC TaqMan probe & $5^{\prime}$-6-FAM-CCCTGGACAAACCATGCCACCAA-BHQ-3' \\
APC1450 forward primer & $5^{\prime}$-agaagtaaaacacctcca-3' \\
APC1450 reverse primer & $5^{\prime}$-gtatcagcatctggaagaa-3' \\
\hline
\end{tabular}

pH 9.0, 6 mM EDTA, $0.5 \mathrm{~N} \mathrm{HCl}$ ) prior to PCR amplifications.

\section{Magnetic Bead Hybrid Capture}

For comparison, human DNA was also isolated from total stool DNA using a magnetic bead-based hybrid capture technology (20) with the following changes to normalize it to RECAP. Briefly, $200 \mathrm{pmol}$ of the biotinylated APC capture probes described above were hybridized overnight at room temperature with $0.2 \mathrm{~mL}$ of denatured stool DNA in a $3 \mathrm{M}$ guanidine isothiocyanate (GITC) solution. The APC sequence/capture probe hybrids were separated from the total stool DNA by binding the hybrids to $3 \mathrm{mg}$ streptavidin-coated magnetic beads (Invitrogen, Carlsbad, CA, USA), attracting the beads to the side wall of the hybridization tube with a magnet and removing the hybridization solution. The beads were then washed four times $(1 \mathrm{M} \mathrm{NaCl}, 10 \mathrm{mM}$ Tris$\mathrm{HCl}$ [pH 7.2], and $1 \mathrm{mM}$ EDTA, $0.1 \%$ Tween 20). The captured DNA was eluted from the magnetic beads using $100 \mu \mathrm{l}$ of $0.1 \mathrm{~N} \mathrm{NaOH}$ and the eluate was neutralized with $10 \mu \mathrm{L}$ of neutralization buffer. Increasing amounts of total stool DNA were processed by proportionally increasing the volume of the GITC solution while maintaining equivalence to RECAP by using 200 pmol of the capture probes, all other steps being the same as described above.

\section{Commercially Available Stool DNA Purification}

Finally, the same samples were also used for DNA purification with the QIAamp DNA Stool Mini kit (Qiagen, Valencia, CA, USA). The kit protocol was performed with the following exceptions. The total DNA fraction precipitated from the stool homogenate, described above, was used as the starting material for the stool kit purification using $0.2 \mathrm{~mL}$ per tube (equivalent to $0.2 \mathrm{~g}$ of original stool). The sample was processed, purified, and eluted from purification spin columns according to manufacturer's instructions. To normalize to RECAP elution volume, the $200 \mu \mathrm{L}$ of Qiagen-purified 


\section{Short Technical Reports}

A

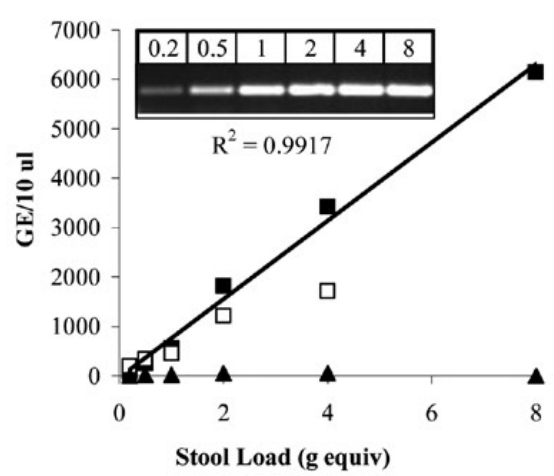

B

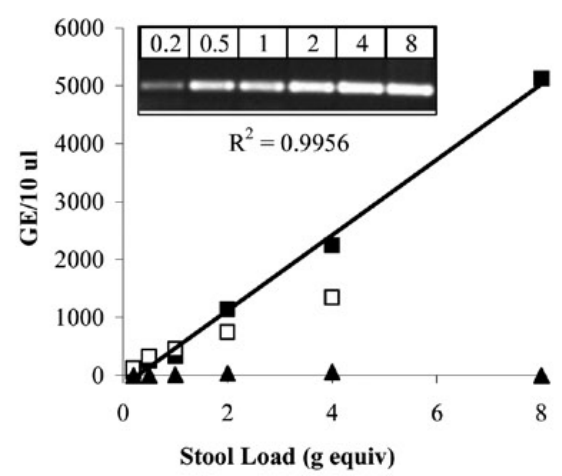

C

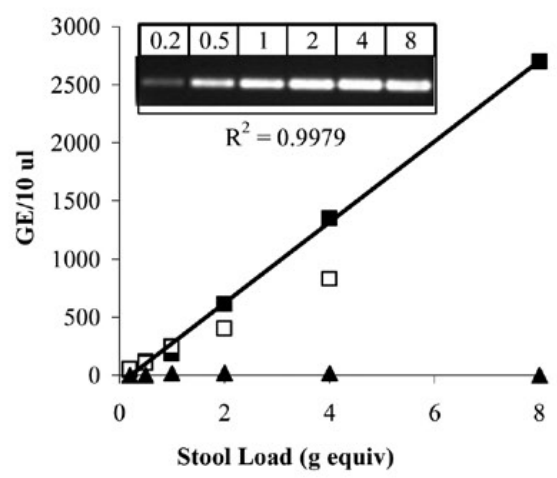

Figure 2. Human DNA recovered from increasing stool load. Increasing volumes of total stool DNA isolated from a single stool from each of three CRC patients (GP-164 (A), 02-8854 (B), and 02-5860 (C)) was applied to the RECAP hybrid capture system ( $\mathbf{\square})$, magnetic bead capture system ( $\square$ ), and the Qiagen DNA Stool Mini kit $(\mathbf{A})$. Human DNA recovered by each method was quantitated with a real-time PCR amplification of the human APC target. The inset pictures show, for comparison, 40-cycle end-point PCR amplifications of human APC sequence (142 bp) recovered with RECAP for the corresponding stool loads from $0.2 \mathrm{~g}$ to $8.0 \mathrm{~g}$. g equiv, a volume (mL) of stool homogenate containing one gram of original undiluted stool sample; GE, genomic equivalents, $95 \%$ confidence intervals.

DNA was ethanol-precipitated and resuspended in $110 \mu \mathrm{l} 0.6 \times \mathrm{TE}$ buffer.

Additionally, in order to investigate the ability to load more than the recommended amount of stool sample onto a QIAamp mini-column, multiple 0.2 $\mathrm{mL}$ aliquots were prepared according to the manufacturer's instructions and the resulting DNA solution from each aliquot was serially applied to a single mini-column. For example, to achieve a $1 \mathrm{~g}$ stool equivalent load, five aliquots were processed and applied to one column. The wash steps and elution steps were done as described by the manufacturer for one column. The 200 $\mu$ l elution volume was normalized to the RECAP elution volume as described above. For the $8 \mathrm{~g}$ stool equivalent amount, 40 stool DNA aliquots were prepared and the resulting DNA solution was applied equally to four QIAamp maxi-columns The QIAamp maxi-column is a larger column with a greater capacity to bind DNA than the QIAamp mini-column. The QIAamp maxi-columns were washed and eluted as described in the manufacturer's suggested protocol for maximum DNA recovery. The maxi-column elutions were combined, ethanol-precipitated, and resuspended in $110 \mu \mathrm{l}$ of $0.6 \times \mathrm{TE}$ to normalize to the RECAP elution volume.

\section{Gene Target Quantification and Cancer Mutation Detection}

The copy number of APC target recovered from each sample was quantified using an iCycler IQ realtime PCR detection system (Bio-Rad Laboratories, Hercules, CA, USA). Duplicate reactions $(50 \mu \mathrm{l})$ consisted of $5 \mu \mathrm{l}$ of DNA, $1 \times$ PCR buffer (Takara Bio; Madison, WI, USA), $0.2 \mathrm{mM}$ dNTPs (Promega, Madison, WI, USA), $0.5 \mu \mathrm{M}$ of sequence-specific primers (IDT; Table 1), $0.2 \mu \mathrm{M}$ of TaqMan dual-labeled probe (IDT; Table 1), and 2.5 U LATaq DNA polymerase (Takara Mirus Bio, Madison, WI, USA). The PCR parameters were $95^{\circ} \mathrm{C}$ for $3.5 \mathrm{~min}$ for denaturation followed by 40 cycles of $95^{\circ} \mathrm{C}$ for $1 \mathrm{~min}, 55^{\circ} \mathrm{C}$ for $1 \mathrm{~min}$, and $72^{\circ} \mathrm{C}$ for $1 \mathrm{~min}$.

PCR amplification of the APC codon 1450 gene sequence adjacent to the APC capture probe was performed on Tetrad Thermal Cyclers (Bio-Rad Laboratories) using $10 \mu \mathrm{L}$ of recovered DNA, $1 \times$ PCR buffer, $0.2 \mathrm{mM}$ dNTPs, $0.5 \mu \mathrm{M}$ of sequence-specific primers (IDT; Table 1), and 2.5 U LATaq DNA polymerase (Takara). After an initial denaturation of $94^{\circ} \mathrm{C}$ for $5 \mathrm{~min}$, reactions were run using 40 cycles consisting of $1 \mathrm{~min}$ at $94^{\circ} \mathrm{C}, 1 \mathrm{~min}$ at $60^{\circ} \mathrm{C}$, and $1 \mathrm{~min}$ at $72^{\circ} \mathrm{C}$, with a final extension of $5 \mathrm{~min}$ at $72^{\circ} \mathrm{C}$.
A specific point mutation in codon 1450 of the PCR-amplified APC sequence was identified using a modified single-base extension (SBE) assay (20). The SBE reaction was analyzed for the mutation with an ABI 3100 capillary electrophoresis system and GenoTyper software (ABI, Foster City, CA, USA). Mutation detection frequency was determined by performing 10 replicate PCR amplifications with DNA recovered from one capture. Each replicate was independently interrogated for the mutation. The frequency of detection was reported as the number of PCR reactions with detectable mutation/ PCR reactions.

\section{RESULTS AND DISCUSSION}

To date, recovering rare human DNA target from stool samples requires the ability to process large amounts of stool (20). The simple method we use to isolate total DNA from stool homogenate removes the majority of the particulate components and can yield upwards of $60 \mu \mathrm{g}$ of mostly bacterial DNA from $1 \mathrm{~g}$ of stool. The stool DNA isolate contains many components that co-precipitate with DNA. These components and the increased DNA concentration recovered from large amounts of stool clog capture probe support 


\section{Short Technical Reports}

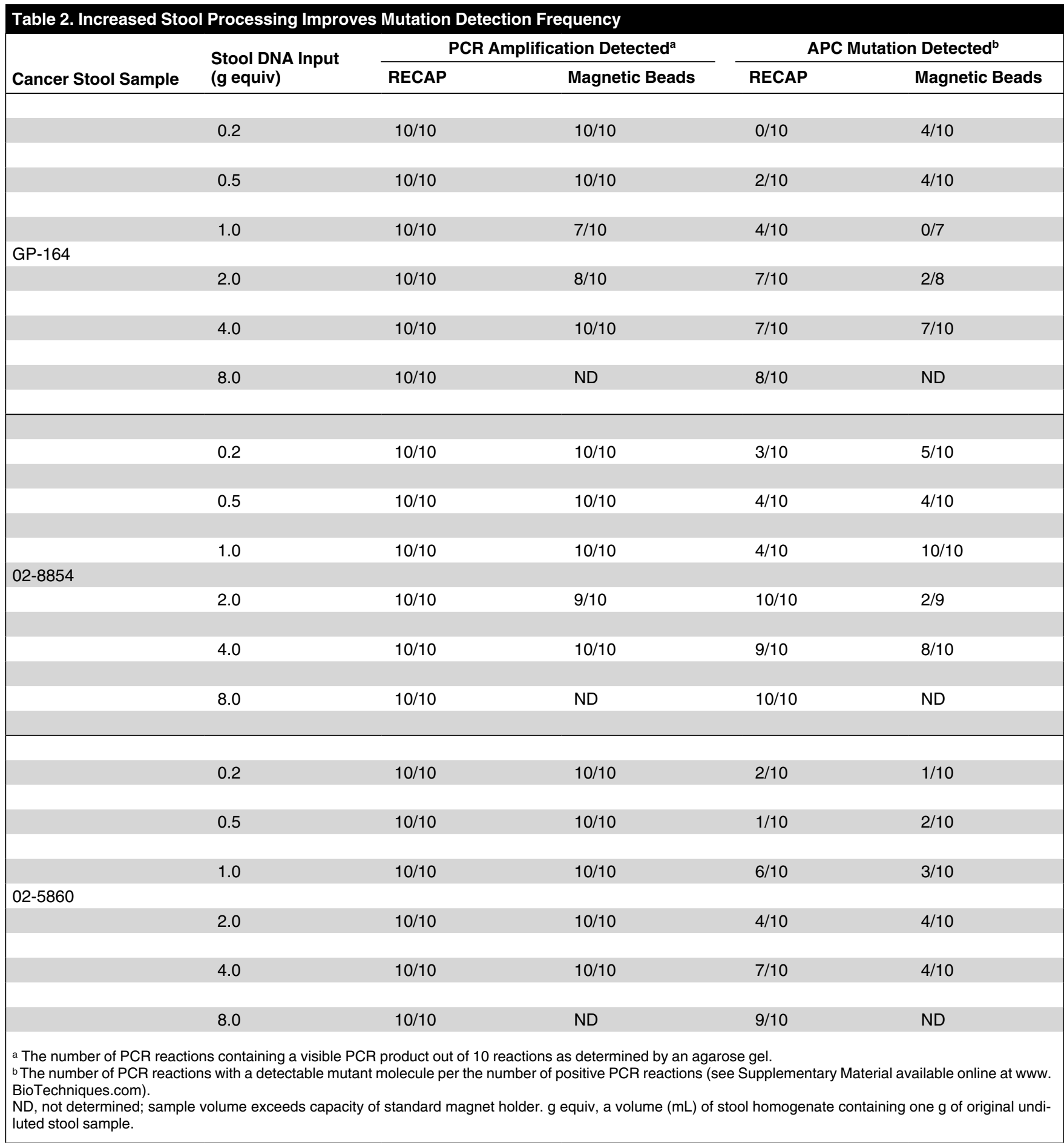


A

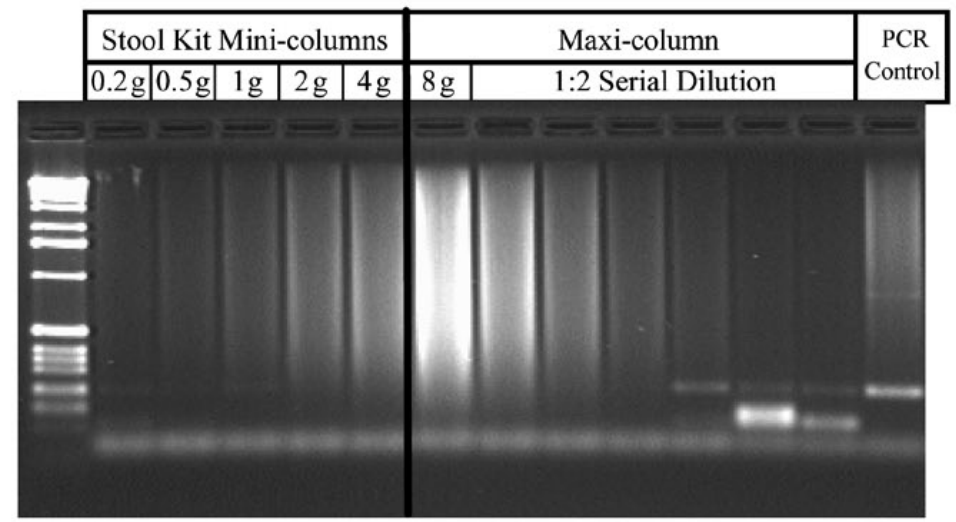

B

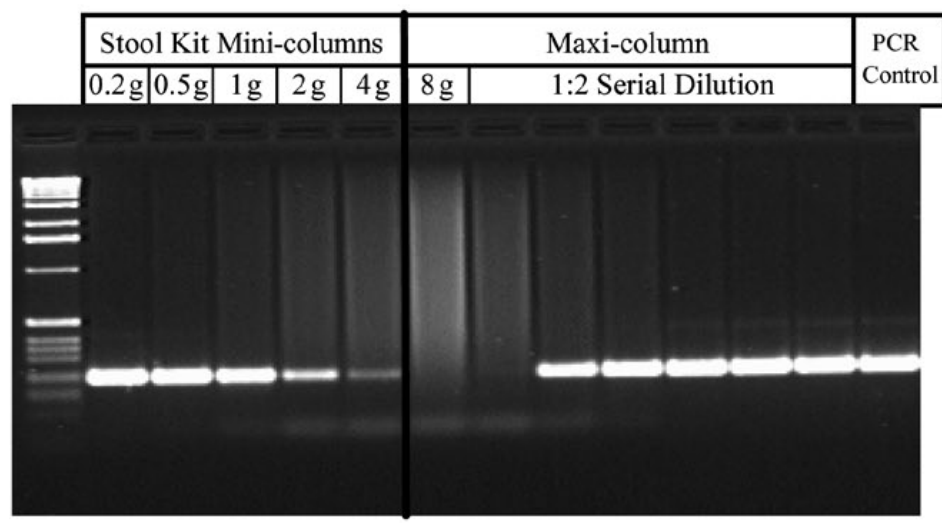

Figure 3. End-point agarose gel analysis of APC PCR amplification using stool DNA derived from commercial purification kits. Agarose gel pictures of PCR amplifications for the APC sequence using stool DNA generated from increasing sample volumes applied to commercial stool DNA purification kits (Qiagen). (A) Amplification using $10 \mu \mathrm{L}$ of undiluted purified DNA from stool sample 02-8854. Also shown are PCR amplifications using undiluted purified DNA and 2-fold serial dilutions recovered from the QIAamp maxi-column. Similar results were found using purified DNA from stool samples GP-164 and 02-5860 (PCR Control, 7 GE-purified human DNA in $2 \mu \mathrm{g}$ purified $E$. coli DNA). (B) Results from purified DNA from stool sample 02-8854 spiked with human DNA at 1250 GE per PCR is also illustrated. (PCR Control, 1250 GE-purified human DNA spike with no stool sample added.) GE, genomic equivalents.

matrices with small pore sizes (unpublished observation). Such matrices are limited in their ability to process large total DNA loads. The polyacrylamide Ultralink beads ( $50-80 \mu \mathrm{m}$ in diameter) provide a rigid support for oligonucleotide capture probes with a bead bed porosity that permits the processing of larger volumes of simply isolated total stool DNA without clogging.

While the high porosity allows unhindered DNA movement, this solid phase capture probe technique provides poor hybridization capture with only a single electrophoretic pass through the capture device (Figure 1). The recovery of APC target sequence is dramatically improved by cycling the sample back and forth through the capture cartridge (Figure 1). Recovery saturation occurs between 10 and 14 electrophoretic cycles so, as standard practice, RECAP is run for 14 cycles to maximize recovery.

The Ultralink beads with immobilized streptavidin have a large capacity for biotinylated capture probe. Using a fluorescently labeled hybridization probe complementary to the sequence of the capture probe attached to the Ultralink beads, we have determined that $100 \mu \mathrm{l}$ of beads can bind up to 8000 pmol of capture probe. In practice, we have found that the minimum amount of probe needed for maximal recovery of human DNA from stool is 200 pmol. Theoretically, 200 pmol of probe have the ability to capture well over $10^{13}$ copies of a gene target and should be in vast excess. This was shown in scale- up experiments by processing up to $8 \mathrm{~g}$ equivalents of total stool DNA (Figure 2 ). Three archived stool homogenates from CRC patients were processed with RECAP, progressively increasing the sample volume to the limit of the RECAP apparatus $(8 \mathrm{~mL})$. The APC genome equivalents recovered by RECAP were linear over the range of sample volumes used; indicating the capture probe was not a limiting factor. Correspondingly, 40-cycle PCR amplification of APC sequence improved with increasing target recovery (Figure 2, insets). As we have found previously, the amount of human DNA recovered per $\mathrm{g}$ of stool varies for different stool samples (20).

We have successfully used a magnetic bead hybrid capture process in previous studies for CRC-associated mutation detection (21-23). In those studies total stool DNA equivalent to $0.12 \mathrm{~g}$ stool was processed. Here we have scaled the process only up to $4 \mathrm{~g}$ stool equivalent, due to a tube volume/size limitation of the magnetic apparatus. As with RECAP, there was a corresponding increase in target recovery with increasing amounts of stool processed. However, the amount of APC target recovered became limiting with larger volumes of total DNA (Figure 2). There were also random PCR failures that did not correlate with stool DNA load amount (Table 2). For those elutions that exhibited failed PCRs, the remaining PCR amplifications were visibly weaker on agarose gel analysis (data not shown), suggesting stool PCR inhibitors. This conclusion is supported by real-time PCR analysis used to quantitate target recovery from the magnetic bead captures. Elutions showing weak or failed end-point PCR amplification showed robust quantification (Figure 2). This seemingly contradictory result is a function of the different PCR amplification sensitivities of the two techniques to stoolspecific PCR inhibitors and is not due to inefficient capture (unpublished observations).

Both hybrid capture systems show increasing APC codon 1450 mutation detection frequency with increasing recovery of APC DNA sequence from stool DNA. In previous studies, using 
an earlier version of hybrid capture $(20,21)$, no mutant APC DNA was detected in these same samples. That the APC 1450 mutation should have been present in the stool samples was independently determined by SBE mutation analysis of CRC tissue obtained during colonoscopy. In those previous studies, total DNA from smaller amounts of stool were used in the hybrid capture and, presumably as a result of stochastic sampling, insufficient mutant molecules were present in the aliquot analyzed. This assumption was confirmed in the scale-up experiments described here. Each hybrid capture was eluted in a final volume of $110 \mu \mathrm{l}$. After $10 \mu \mathrm{l}$ was used for total human DNA capture quantification by real-time PCR, the remaining DNA was distributed equally in 10 PCR amplification reactions. This was done to ensure the detection of any mutant molecules in the capture elution. Scale-up increased the mutation detection frequency from $0 \%$ to $30 \%$ for $0.2 \mathrm{~g}$ stool to $80 \%$ to $100 \%$ for $8.0 \mathrm{~g}$ stool (Table 2). RECAP showed more consistent mutation detection in response to increased target recovery than the magnetic bead capture system. The magnetic bead method suffered from a greater frequency of PCR failures and weak PCR amplifications, which may have contributed to reduced mutation detection. The consistent RECAP performance is likely due to improvements in the purity of the captured DNA, resulting in robust PCR compared with that seen with magnetic bead capture.

Detection of rare DNA molecules in a background of large numbers of nontarget DNA molecules can be a great challenge when total DNA purification is the sample preparation approach. There are commercially available products that purify total DNA from biological samples with heterogeneous DNA populations. The QIAamp DNA Stool Mini kit is designed specifically for isolation of total DNA from stool samples. The kit uses column purification with a proprietary InhibitEX tablet to neutralize the PCR inhibitors found in stool. While the kit works well purifying total DNA from stool, which is primarily bacterial, we have had only sporadic success amplifying the co- purifying human DNA targets. This is likely due to the underrepresentation of human DNA in the recommended $0.2 \mathrm{~g}$ of stool used per mini-column purification. We compared the effectiveness of the QIAamp DNA Stool Mini kit to human sequence-specific hybrid capture. This was done by doing a similar scale-up of sample volume with the same three archived cancer stools and by applying multiple tubes of processed stool to a single QIAamp mini-column. Measurement of DNA concentration by $\mathrm{OD}_{260}$ indicated that the mini-columns linearly increased DNA yield, until becoming saturated at the $2 \mathrm{~g}$ stool equivalent load (data not shown). However, using the much larger QIAamp maxi-columns, $\mathrm{OD}_{260}$ measurement of DNA concentration indicated that we were able to purify on average 43-fold more total stool DNA from $8 \mathrm{~g}$ stool than from the recommended $0.2 \mathrm{~g}$ of stool for the minicolumn.

Despite the increase in DNA yield, end-point PCR using these samples showed very little human APC sequence amplification (Figure 3A). Results are shown for cancer stool sample 02-8854, but were similar for the other stools tested. Faint PCR bands were seen only at high dilutions of maxicolumn purified DNA. Similarly, realtime PCR quantification detected little to no APC sequence and again only at high dilutions of maxi-column purified DNA. Robust PCR amplification of the APC sequence when additional human DNA is spiked into the eluted stool DNA demonstrated that the columns successfully purified the total stool DNA of PCR inhibitors (Figure 3B). However, in samples with the highest DNA concentration, spiked DNA amplifications were still inhibited. This indicates that PCR amplification can become inhibited with excessive amounts of total stool DNA, possibly because of aberrant priming on the large quantities of nontarget DNA. Repeating the scale-up using fresh stools homogenized for DNA isolation as described in the manufacturer's protocol for large amounts of stool showed similar poor results.

We have shown in this report that sequence-specific hybridization capture methods are more efficient in the recovery and subsequent amplification of rare DNA molecules from heterogeneous DNA samples than methods that purify the total DNA. The removal of extraneous DNA and thus the enrichment of target leads to more robust PCR. The RECAP electrophoretic hybridization capture process is especially suited for minimally purified complex heterogeneous DNA samples. We have demonstrated that this process can successfully recover rare DNA molecules from both small $(0.2 \mathrm{~g})$ and large $(8 \mathrm{~g})$ initial quantities of stool samples.

The magnetic bead-based hybridization capture method has been used to effectively recover human DNA from stool (21-23). However, as shown in this report and in previous unpublished studies (EXACT Sciences), large stool volumes are often associated with incomplete removal of PCR inhibitors, compromising downstream PCR reactions. While the addition of postcapture purification steps can address this issue, it would add extra time and expense to the magnetic bead-based process. This extra effort required could be offset with the ease of adapting the magnetic bead processing to highthroughput automation.

As the Ultralink beads used in this study have a very high binding capacity, additional capture probes can be incorporated in a multiplex format to simultaneously capture multiple DNA targets, greatly increasing RECAP's versatility. Currently, we are validating RECAP with a blinded set of clinical stool samples for a multiplex capture of several cancer-related human gene targets. Although developed for human DNA capture in stool, RECAP is a generic platform technology whose specificity is only dependent on the bound capture probes. RECAP could be applied to other biological samples looking for rare DNA targets in a background of larger amounts of heterogeneous DNA molecules and where PCR inhibitors are also an issue. RECAP could also be optimized for RNA or protein capture by attaching the appropriate ligand to the streptavidin beads. 


\section{ACKNOWLEDGMENTS}

J.K.M. and J.A.S. have contributed equally to this work. We would like to thank John Millholland and Barry M. Berger for their critical review of the manuscript. A special thanks to Patty David for her help in the development of RECAP.

\section{COMPETING INTERESTS STATEMENT}

J.K.M., J.A.S., and K.H.D. are employees of EXACT Sciences Corporation and are all shareholders of the company. D.H.W. and A.P.S. were formerly employed by EXACT Sciences and performed this work while employed there. During that time they were compensated with options for EXACT Sciences stock.

\section{REFERENCES}

1. Schmitt, J.J. and B.N. Cohen. 1983. Quantitative isolation of DNA restriction fragments from low-melting agarose by Elutip-d affinity chromatography. Anal. Biochem. 133:462-464.

2. Attal, J., C. Puissant, and L.M. Houdebine. 1990. An improvement of a rapid method using Qiagen columns to purify plasmids. BioTechniques 8:269-271

3. Picard, C., C. Ponsonnet, E. Paget, X. Nesme, and P. Simonet. 1992. Detection and enumeration of bacteria in soil by direct DNA extraction and polymerase chain reaction. Appl. Environ. Microbiol. 58:2717-2722.

4. Kramvis, A., S. Bukofzer, and M.C. Kew. 1996. Comparison of hepatitis B virus DNA extractions from serum by the QIAamp blood kit, GeneReleaser, and the phenol-chloroform method. J. Clin. Microbiol. 34:2731-2733.

5. Krajden, M., P. Shankaran, C. Bourke, and W. Lau. 1996. Detection of cytomegalovirus in blood donors by PCR using the digene SHARP signal system assay: effects of sample preparation and detection methodology. J. Clin. Microbiol. 34:29-33.

6. Vogelstein, B. and D. Gillespie. 1979. Preparative and analytical purification of DNA from agarose. Proc. Natl. Acad. Sci. USA 76:615-619.

7. Boom, R., C.J. Sol, M.M. Salimans, C.L. Jansen, P.M. Wertheim-van Dillen, and J. van der Noordaa. 1990. Rapid and simple method for purification of nucleic acids. J. Clin. Microbiol. 28:495-503.

8. Hawkins, T.L., T. O'Connor-Morin, A. Roy, and C. Santillan. 1994. DNA purification and isolation using a solid-phase. Nucleic Acids Res. 22:4543-4544.

9. Elkin, C.J., P.M. Richardson, H.M. Fourcade, N.M. Hammon, M.J. Pollard, P.F. Predki, T. Glavina, and T.L. Hawkins.
2001. High-throughput plasmid purification for capillary sequencing. Genome Res. 11:1269-1274.

10. Deggerdal, A. and F. Larsen. 1997. Rapid isolation of PCR-ready DNA from blood, bone marrow and cultured cells, based on paramagnetic beads. BioTechniques 22:554557.

11. Saukkoriipi, A., T. Kaijalainen, L. Kuisma, A. Ojala, and M. Leinonen. 2003. Isolation of pneumococcal DNA from nasopharyngeal samples for real-time, quantitative PCR: comparison of three methods. Mol. Diagn. 7:9-15.

12. Morrissey, D.V., M. Lombardo, J.K. Eldredge, K.R. Kearney, E.P. Groody, and M.L. Collins. 1989. Nucleic acid hybridization assays employing dA-tailed capture probes. I. Multiple capture methods. Anal. Biochem. 181:345-359.

13. Gilgen, M., B. Wegmuller, P. Burkhalter, H.P. Buhler, U. Muller, J. Luthy, and U. Candrian. 1995. Reverse transcription PCR to detect enteroviruses in surface water. Appl. Environ. Microbiol. 61:1226-1231.

14. Tsai, Y.L., J.Y. Le, and B.H. Olson. 2003. Magnetic bead hybridization to detect enterotoxigenic Escherichia coli strains associated with cattle in environmental water sources. Can. J. Microbiol. 49:391-398.

15. Fuentes, M., C. Mateo, A. Rodriguez, M. Casqueiro, J.C. Tercero, H.H. Riese, R. Fernandez-Lafuente, and J.M. Guisan. 2005. Detecting minimal traces of DNA using DNA covalently attached to superparamagnetic nanoparticles and direct PCRELISA. Biosens Bioelectron. Aug. 29 [Epub ahead of print].

16. Mangiapan, G., M. Vokurka, L. Schouls, J. Cadranel, D. Lecossier, J. van Embden, and A.J. Hance. 1996. Sequence capturePCR improves detection of mycobacterial DNA in clinical specimens. J. Clin. Microbiol. 34:1209-1215.

17. Wages, J.M., Jr., G.M. Wages, P. Matthews, D. Weller, and J. Summerton. 1997. Affinity purification of RNA: sequence-specific capture by nonionic morpholino probes. BioTechniques 23:1116-1121.

18. Muir, P., F. Nicholson, M. Jhetam, S. Neogi, and J.E. Banatvala. 1993. Rapid diagnosis of enterovirus infection by magnetic bead extraction and polymerase chain reaction detection of enterovirus RNA in clinical specimens. J. Clin. Microbiol. 31:31-38.

19. Millar, D.S., S.J. Withey, M.L. Tizard, J.G. Ford, and J. Hermon-Taylor. 1995. Solidphase hybridization capture of low-abundance target DNA sequences: application to the polymerase chain reaction detection of Mycobacterium paratuberculosis and Mycobacterium avium subsp. silvaticum. Anal. Biochem. 226:325-330.

20. Whitney, D., J. Skoletsky, K. Moore, K. Boynton, L. Kann, R. Brand, S. Syngal, M. Lawson, et al. 2004. Enhanced retrieval of DNA from human fecal samples results in improved performance of colorectal cancer screening test. J. Mol. Diagn. 6:386-395.

21. Ahlquist, D.A., J.E. Skoletsky, K.A. Boynton, J.J. Harrington, D.W. Mahoney, W.E. Pierceall, S.N. Thibodeau, and A.P.
Shuber. 2000. Colorectal cancer screening by detection of altered human DNA in stool: feasibility of a multitarget assay panel. Gastroenterology 119:1219-1227.

22. Imperiale, T.F., D.F. Ransohoff, S.H. Itzkowitz, B.A. Turnbull, and M.E. Ross. 2004. Fecal DNA versus fecal occult blood for colorectal-cancer screening in an averagerisk population. N. Engl. J. Med. 351:27042714.

23. Traverso, G., A. Shuber, B. Levin, C. Johnson, L. Olsson, D.J. Schoetz, Jr., S.R. Hamilton, K. Boynton, et al. 2002. Detection of APC mutations in fecal DNA from patients with colorectal tumors. N. Engl. J. Med. 346:311-320.

Received 18 May 2007; accepted 25 October 2007.

D.H.W.'s present address is U.S. Genomics, Woburn, MA, USA, and A.P.S.'s present address is Predictive Biosciences, Lexington, MA, USA.

Address correspondence to J. Kent Moore, EXACT Sciences Corporation, 100 Campus Dr., Marlborough, MA 01752, USA. e-mail: kmoore@exactsciences.com

To purchase reprints of this article, contact: Reprints@BioTechniques.com 